\title{
PENERAPAN CUSTOMER RELATIONSHIP MANAGEMENT (CRM) PADA SISTEM INFORMASI PELAYANAN JASA METEOROLOGI BERBASIS WEB
}

\author{
Imam Agustian Nugraha ${ }^{1}$, Vidilla Rosalina ${ }^{2}$, Suherman ${ }^{3}$ \\ 1,2,3 Jurusan Teknik Informatika, Fakultas Teknologi Informasi, Universitas Serang Raya \\ Jl. Raya Serang - Cilegon Km.05 (Taman Drangong), Serang - Banten \\ ${ }^{I}$ imamagustiannugraha@ymail.com, \\ ${ }^{2}$ vidila.suhendarsah@gmail.com, \\ ${ }^{3}$ suherman.unsera@gmail.com
}

\begin{abstract}
Abstrak
Pelayanan jasa informasi meteorologi yang cepat, tepat akurat dan mudah dipahami merupakan salah satu tugas Stasiun Meteorologi (STAMET) Kelas I Maritim Serang. Namun berdasarkan wawancara dan observasi yang dilakukan, menunjukan bahwa pelayanan yang dilakukan belum efisien dan praktis karena pengguna jasa harus datang ke kantor untuk memperoleh data yang diinginkan. Selain itu petugas pelayanan masih mencatat transaksi dalam buku yang kemudian diketik kembali pada aplikasi Microsoft Word, dan mengalami kesulitan dalam mencari berkas yang akan diberikan kepada pengguna jasa. Penelitian ini bertujuan untuk membuat sistem yang dapat membantu tugas STAMET untuk meningkatkan pelayanan jasa meteorologi dengan menggunakan pendekatan Customer Relationship Management (CRM). Metode pengembangan yang digunakan yaitu model prototype dengan perancangan diagram Unified Modelling Language (UML). Sistem dibuat menggunakan Framework Codeigniter dengan Bahasa pemograman Hypertext Preprocessing (PHP) sebagai Server side Programing dan MySQL sebagai Database Server. Metode pengujian sistem yang digunakan adalah Blackbox. Hasil akhir yang diharapkan adalah sebuah sistem informasi pelayanan jasa meteorologi berbasis Web, yang dapat membantu pengguna jasa mendapatkan informasi meteorologi, mempermudah petugas dalam memberikan pelayanan jasa, pembuatan jadwal kunjungan atau pertemuan, mengajukan komplain pelayanan jasa, memberikan kritik dan saran serta mengukur kepuasan pengguna jasa terhadap pelayanan yang diberikan oleh petugas STAMET Kelas I Maritim Serang.
\end{abstract}

Kata Kunci: Customer Relationship Management (CRM), Pelayanan Jasa Meteorologi, Sistem

\section{PENDAHULUAN}

Stasiun Meteorologi (STAMET) Kelas I Maritim Serang merupakan salah satu Unit Pelaksana Teknis (UPT) Badan Meteorologi Klimatologi dan Geofisika di provinsi Banten. Dalam pelaksanaan tugas dan fungsinya mengacu kepada Undang-undang Nomor 31 Tahun 2009 Tentang BMKG dan Peraturan Kepala Badan Meteorologi, Klimatologi, dan Geofisika Nomor 9 Tahun 2014 tentang Uraian Tugas Stasiun Meteorologi. STAMET Kelas I Maritim Serang memiliki kewajiban memberikan pelayanan jasa untuk keperluan khusus atas permintaan pengguna jasa dan atau atas berdasarkan kerja sama dengan instansi terkait di wilayah yang menjadi tanggung jawabnya, sebagaimana tercantum dalam Peraturan Kepala BMKG Nomor 9 Tahun 2014 tentang uraian tugas Stasiun Meteorologi Kelas I, Romawi I, Poin C.8.
Dalam menjalankan tugas dan fungsinya, STAMET Kelas I Maritm Serang berusaha memberikan layanan informasi Meteorologi yang cepat, tepat, akurat dan mudah dipahami. Namun pelaksanaannya masih belum efisien dan praktis karena pengguna jasa harus datang secara langsung ke kantor STAMET Kelas I Maritim Serang untuk mendapatkan informasi yang diinginkan. Hal tersebut menimbulkan beberapa kendala bagi pengguna jasa, dimana banyak menyita waktu, biaya dan tenaga untuk mendapatkan informasi yang dibutuhkan. Selain itu proses pelayanan jasa yang dilakukan oleh petugas secara keseluruhan masih menggunakan cara manual, yaitu petugas menulis data yang masuk pada buku yang kemudian diketik kembali melalui aplikasi Microsoft Word. Hal tersebut dapat menyebabkan lamanya proses pelayanan jasa, dan kesulitan dalam melakukan pencarian berkas layanan jasa yang sudah selesai dibuat untuk diberikan 
kepada pengguna jasa di karenakan berkas layanan yang bertumpuk dalam berkas lainnya.

Untuk meningkatkan proses pelayanan jasa bagi pengguna, pada penelitian ini akan menggunakan pendekatan Customer Relationship Management (CRM) atau Manajemen Hubungan Pelanggan. Penggunaan CRM ini dipilih karena selain dapat meningkatkan pelayanan, CRM juga dapat memperbaiki dan mengelola pelayanan sesuai dengan harapan dan Loyalitas Pelanggan. Selain itu penggunaan pendekatan CRM pada penelitian ini didukung oleh penelitian terdahulu yang dilakukan oleh Imasari dan Nursalim yang menunjukan hasil bahwa, "terdapat hubungan yang signifikan antara variabel Manajemen Hubungan Pelanggan dengan Loyalitas Pelanggan. Penelitian tersebut menunjukan bahwa manajemen Hubungan Pelanggan dapat membentuk citra perusahaan yang positif di benak pelanggan. Strategi manajemen hubungan pelanggan yang dilakukan perusahaan mampu membentuk tingkat Loyalitas Pelanggan yang merasa puas dengan kinerja perusahaan" [1]. Selain efektif digunakan untuk perusahaan, CRM juga dapat diimplementasikan pada pemerintahan yang memiliki lingkungan berbeda, dengan merancang CRM secara khusus mengikuti kebutuhan dalam pemerintahan. CRM yang akan diimplementasikan pada STAMET Kelas Maritim I Serang yaitu untuk mengukur tingkat kepuasan serta kritik dan saran pengguna terhadap kinerja petugas layanan agar lebih baik dan untuk memudahkan pengguna dalam melakukan komplain terhadap layanan yang di dapatkan.

Menurut Berson ada tiga jenis atau aplikasi CRM secara garis besar, "yaitu operational CRM, analytical CRM, dan collaborative CRM" [2]. CRM yang digunakan pada penelitian ini adalah operational CRM yang disesuaikan dengan kebutuhan pada tempat penelitian. Fokus operational CRM adalah pada otomatisasi dan peningkatan pada pelayanan terhadap pelanggan. Otomatisasi yang dimaksud mencakup otmatisasi penjualan, otomatisasi pemasaran, dan otomatisasi pelayanan. Penelitian ini fokus pada otomatisasi pelayanan karena menyesuaikan dengan kebutuhan pada tempat penelitian yaitu membuat fitur untuk menentukan tingkat kepuasan, kritik dan saran pengguna terhadap kinerja petugas layanan, serta fitur komplain untuk layanan yang sudah didapatkan demi tercapainya pelayanan yang lebih baik. Oleh karena itu, penerapan operational CRM ini sangat penting untuk meningkatkan kualitas pelayanan informasi dan jasa meteorologi.

Berdasarkan uraian di atas, maka penelitian ini diberi judul "Rancang Bangun Sistem Informasi
Pelayanan Jasa Meteorologi Berbasis Web Menggunakan Pendekatan Customer Relationship Management". Dengan adanya penelitian ini diharapkan dapat meningkatkan efisiensi, transparansi, dan akuntabilitas layanan jasa Meterologi di STAMET Kelas I Maritim Serang, serta STAMET Kelas I Maritim Serang mendapatkan loyalitas dari pengguna jasa informasi meteorologi. Loyalitas yang dimaksud adalah pengguna jasa mendapatkan kepuasan dan kepercayaan atas pelayanan jasa informasi meteorologi melalui sistem yang akan dibuat sehingga pengguna jasa terus menggunakan sistem dan memberikan kesan positif kepada masyarakat yang belum menggunakan sistem.

Tujuan dari penelitian ini adalah merancang sistem infromasi pelayanan jasa meteorologi berbasis web menggunakan pendekatan Customer Relationship Management (CRM) dengan harapan dapat meningkatkan efisiensi, transparansi, dan akuntabilitas layanan jasa Meterologi di STAMET Kelas I Maritim Serang berdasarakan feedback dari pengguna jasa.

Terdapat beberapa penelitian terdahulu berupa jurnal yang terkait dengan penelitian yang dilakukan penulis.

Rosalina V, dkk, melakukan penelitian tentang "Electronic Customer Relationship Management (ECRM) di berbagai bidang, yaitu Pengelolaan Sampah, UMKM, Smartcity dll, di mana kepuasan customer atau masyarakat adalah menjadi titik keberhasilan pendekatan Customer Relationship Management (CRM) untuk memberikan pelayanan yang efektif dan efisien dengan kepuasan masyarakat yang terukur [312].

Prasetyaningrum (2015), melakukan penelitian tentang "Rancang Bangun E-CRM pada Perbankan Berbasis WEB 2.0 (Studi Kasus Bank BPD DIY Cabang Utama Yogyakarta)". Perkembangan teknologi informasi turut serta merubah paradigma bisnis, product oriented menjadi customer oriented. Customer Relationship Management (CRM) merupakan strategi bisnis yang mengintegrasikan proses bisnis dengan konsumen, proses bisnis dan teknologi pendukung untuk memperoleh customer retention, selanjutnya berkembang menjadi Social CRM BPD DIY Kantor Cabang utama yang terletak di tengah kota mempunyai pertumbuhan jumlah nasabah dari tahun 2013 sampai dengan 2014 sejumlah 4.3\% dan ada pengurangan jumlah rekening dibawah $1 \%$. Oleh sebab itu Bank BPD DIY dituntut untuk mengutamakan kualitas pelayanan pada nasabah. Pada penelitian ini, aplikasi E-CRM dibuat bagi para pengguna, dalam hal ini untuk meningkatkan hubungan dan kualitas pelayanan pada nasabah salah 
satunya layanan keluhan nasabah terhadap pelayanan Bank secara cepat, akurat dan efektif. Metode yang digunakan adalah metode metodologi pengembangan software yang banyak dikembangkan waterfall. Penelitian ini menghasilkan sistem E-CRM untuk menjalin relasi dengan nasabah melalui pemanfaatan teknologi web dan mengenalkan pendekatan yang berbeda dalam menjalin hubungan relasi dengan nasabah khususnya dalam mengenai pengaduan nasabah melalui social web guna meningkatkan kualitas pelayanan terhadap nasabah dan mempertahankan nasabah yang telah ada serta membuat salah satu aplikasi E-CRM untuk mendukung strategi Bank BPD DIY. [13].

Aziz \& Hasugian (2019), melakukan penelitian tentang "Operational Customer Relationship Managemenet pada Sari Good Bakery”. Pelayanan pelanggan yang berjalan pada Sari Good Bakery masih dilakukan secara sederhana. Promosi produk dilakukan dengan pemasangan spanduk pada toko mereka, kemudian melakukan promosi dari mulut ke mulut sehingga produk cenderung hanya dikenal oleh masyarakat di sekitar toko dan penyampaian promosi cenderung mengalir dengan lambat. Lalu penyampaian komentar pelanggan mengenai pelayanan dan produk melalui tatap muka langsung maupun melalui telepon atau SMS. Cara pelayanan tersebut terkadang berakibat terlupakannya komentar dikarenakan belum tersedianya fasilitas untuk menampung komentar tersebut sehingga berpotensi mengalami berkurangnya pelanggan. Solusi untuk mengatasi masalah tersebut yaitu dengan membangun Operational Customer Relationship Management. Metode penelitian yang digunakan yaitu metode penelitian deskriptif kualitatif dengan melakukan wawancara dan observasi. Operational CRM ini menggunakan metode pendekatan Object Oriented Programming dan menggunakan metode pengembangan prototype. Operational CRM yang dibangun dapat meningkatkan pelayanan pelanggan seperti melakukan promosi secara luas dan menyimpan feedback pada situs web. [14].

Adlan, Agustin, \& Efendi, (2019), melakukan penelitian tentang "Rancangan Website E-CRM (Electronics Customer Relationship Managemenet) Pada House of Smith Pekanbaru". CRM (Customer Relationship Management) merupakan cara untuk pengelolaan relasi antara sebuah perusahaan di dalam konsumsi produk atau jasa yang diproduksi perusahaan tersebut. Berkembangnya teknologi, metode CRM pun mulai dikembangkan menjadi Electronic Customer Relationship Management (ECRM). Banyaknya varian produk yang ditawarkan oleh House of Smith dapat dimanfaatkan sebagai strategi unggulan dalam menjaga loyalitas pelanggan. Perancangan aplikasi E-CRM pada House of Smith adalah membantu perusahaan mengetahui kebutuhan pelanggan secara personal serta mampu memberikan pelayanan yang sesuai dengan karakter konsumen dan memberikan informasi yang dibutuhkan, sehingga perusahaan dapat mempertahankan pelanggan yang sudah ada dan mendapatkan pelanggan baru. Metode penelitian yang digunakan adalah observasi dan wawancara langsung ke House of Smith. Hasil dari analisa dan perancangan aplikasi E-CRM berbasis web ini adalah membantu House of Smith untuk memenuhi kebutuhan pelanggan guna meningkatkan kepuasan pelanggan sehingga tetap menjadi pelanggan setia. Aplikasi E-CRM ini merupakan alat interaksi yang menciptakan hubungan antara perusahaan dengan pelanggan menjadi lebih baik. [15].

Dari beberapa penelitian yang telah dilakukan sebelumnya tiga penelitian memiliki judul yang sama dengan penelitian ini yaitu sistem informasi pelayanan dimana satu penelitian untuk non pemerintahan dan dua penelitian ditujukan untuk pemerintahan, dimana satu satu penelitian tersebut di instansi yang serupa yaitu Badan Meteorologi, Klimatologi, dan Geofisika (BMKG) hanya saja berbeda dalam pelayanan yang diberikan. Selain tiga penelitian di atas, empat penelitian menyinggung mengenai CRM atau (Customer Relationship Management). Berdasarkan hal tersebut, maka penelitian-penelitian yang telah dijelaskan sebelumnya dapat dikaitkan dengan penelitian yang akan dilakukan oleh penulis. Metode yang digunakan dalam penelitian ini menggunakan metode prototyping dimana dalam pengumpulan data dilakukan melalui wawancara langsung kepada petugas layanan STAMET Kelas I Maritim Serang sebagai objek penelitian untuk mengetahui masalah-masalah yang sedang terjadi saat penelitian berlangsung. Metode prototyping di pilih karena cocok digunakan untuk menjabarkan kebutuhan pelanggan secara lebih detail, pelanggan sering kali kesulitan menyampaikan kebutuhannya secara detail tanpa melihat gambaran yang jelas. Dalam prosesnya, penulis mendengarkan masalah-masalah yang ada lalu menganalisa, merancang sistem dan membuatnya. Kemudian penulis kembali kepada petugas layanan STAMET Kelas I Maritim Serang untuk mengetahui apakah prototype sistem yang dibuat sesuai dengan kebutuhan atau tidak dengan batasan-batasan masalah yang telah ditetapkan, sehingga terjadi proses pengulangan sampai penelitian ini benar-benar sesuai dengan kebutuhan petugas layanan agar bisa diimplementasikan di STAMET Kelas I Maritim Serang. 


\subsection{Sistem informasi}

Sistem informasi merupakan gabungan dari empat bagian utama, keempat bagian utama tersebut mencakup perangkat lunak (software), perangkat keras (hardware), infrastruktur, dan Sumber Daya Manusia (SDM) yang terlatih. Keempat bagian utama ini saling berkaitan untuk menciptakan sebuah sistem yang dapat mengolah data menjadi informasi yang bermanfaat [16].

\subsection{Customer Relationship Managemenet (CRM)}

Rigo et al. (2016), Adikram (2016), dan Wali et al. (2015) mendefinisikan Customer Relationship Management (CRM) atau Manajemen Hubungan Pelanggan sebagai kepuasan terhadap sikap pelanggan terhadap penyedia layanan, atau reaksi emosional terhadap perbedaan antara apa yang diantisipasi pelanggan dan apa yang mereka terima, mengenai pemenuhan beberapa kebutuhan, tujuan atau keinginan. [1].

\subsection{Unified Modeling Language (UML)}

UML merupakan bahasa visual untuk pemodelan dan komunikasi mengenai sebuah sistem dengan menggunakan diagram dan teks-teks pendukung. UML hanya berfungsi untuk melakukan pemodelan. Jadi pengunaan UML tidak terbatas pada metodologi tertentu, meskipun pada kenyataanyya UML paling banyak digunakan pada metodologi berorientasi objek [17].

\subsection{Blackbox Testing}

Black-box Testing atau pengujian kotak hitam yaitu menguji perangkat lunak dari segi spesifikasi fungsional tanpa menguji desain dan kode program. Pengujian dimaksudkan untuk mengetahui apakah fungsi-fungai, masukan, dan keluaran dari perangkat lunak sesuai dengan spesifikasi yang dibutuhkan [17].

\section{METODOLOGI PENELITIAN}

Adapun metode yang penulis gunakan untuk mengembangkan sistem informasi pelayanan jasa meteorologi ini adalah metode Prototype.

Menurut Mulyanto (2009) Metode prototype sangat baik digunakan untuk menyelesaikan masalah kesalahpahaman antara user dan analis yang timbul akibat user tidak mampu mendefinisikan secara jelas kebutuhannya [18].

Menurut Ogedebe (2012), prototyping dimulai dengan pengumpulan kebutuhan, melibatkan pengembang dan pengguna sistem untuk menentukan tujuan, fungsi, dan kebutuhan operasional sistem [19].

Langkah-langkah dalam prototyping adalah sebagai berikut :

1. Pengumpulan Kebutuhan

2. Membangun Prototype

3. Evaluasi Prototype

4. Mengkodekan Sistem

5. Menguji SIstem

6. Evaluasi Sistem

7. Implementasi Sistem

\section{HASIL DAN PEMBAHASAN}

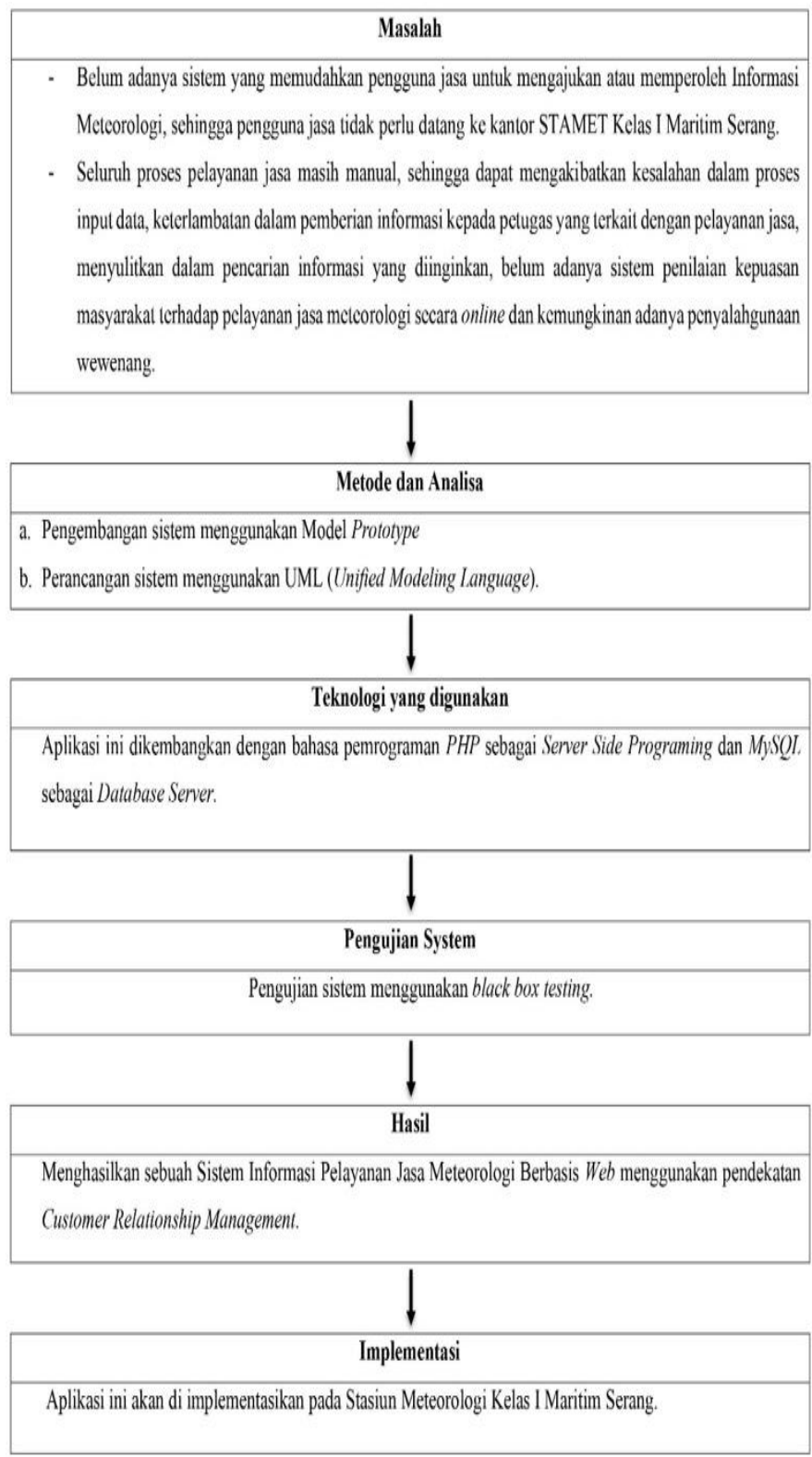

Gambar 1. Kerangka Pemikiran 


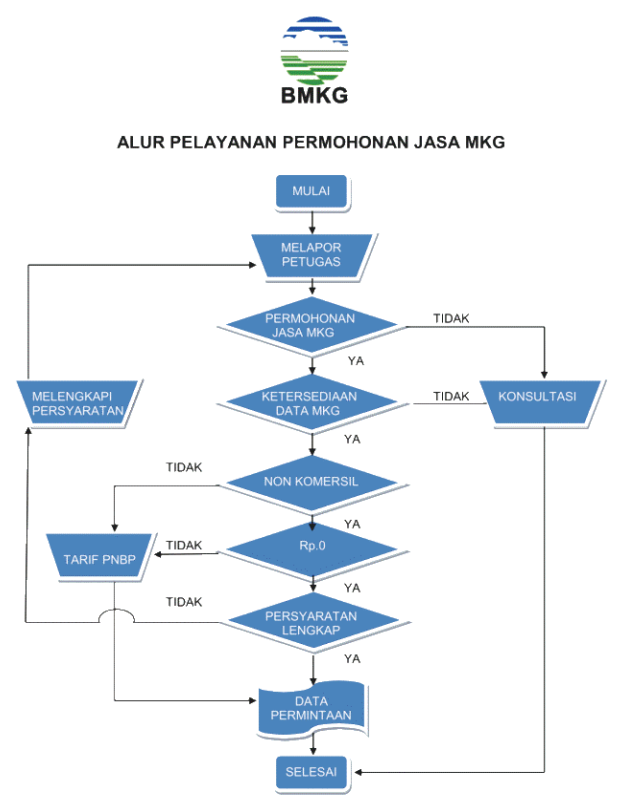

Gambar 2. Flowchart Sistem yang Berjalan

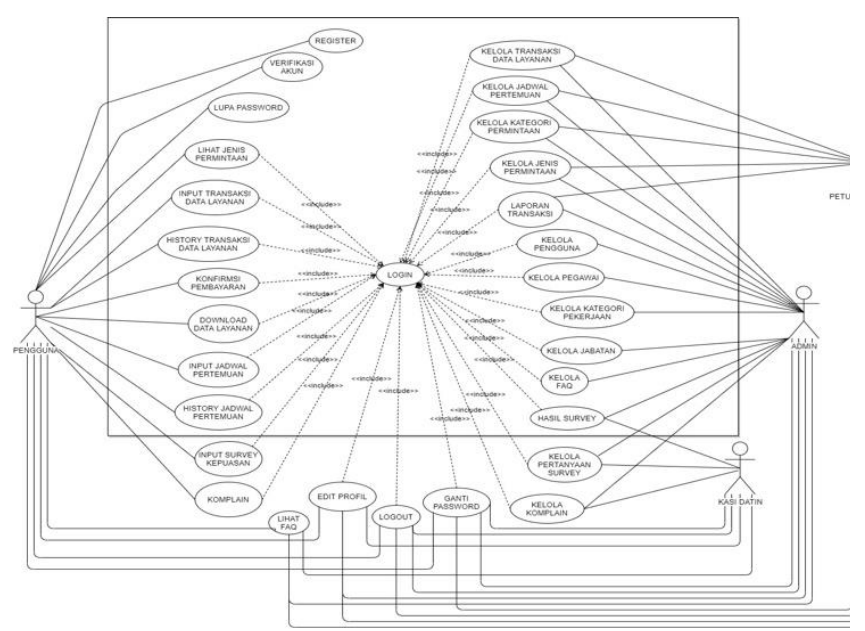

Gambar 3. Use Case Diagram

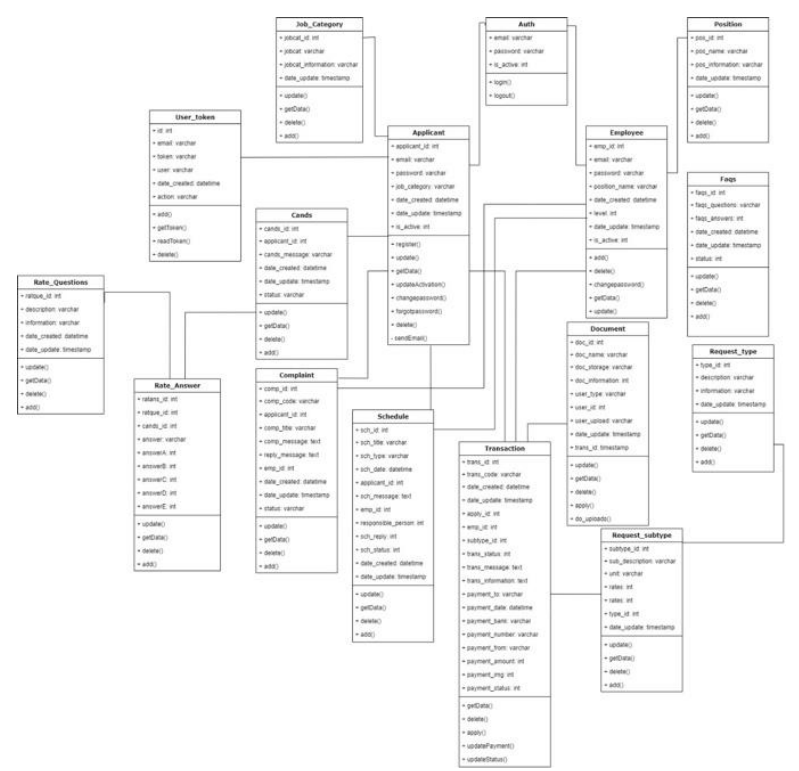

Gambar 4. CLass Diagram
Sistem yang diberi nama Sistem Informasi Pelayanan Jasa Meteorologi (SIPJAMET) ini merupakan sistem berbasis web yang dirancang dan dibangun untuk mempermudah pengguna jasa atau masyarakat di wilayah Banten dalam mengajukan atau memperoleh informasi Meteorologi seperti data curah hujan, musim kemarau, dan data lainnya, yang bersumber dari Stasiun Meteorologi Kelas I Maritim Serang.

Berikut ini tampilan halaman website untuk Admin:

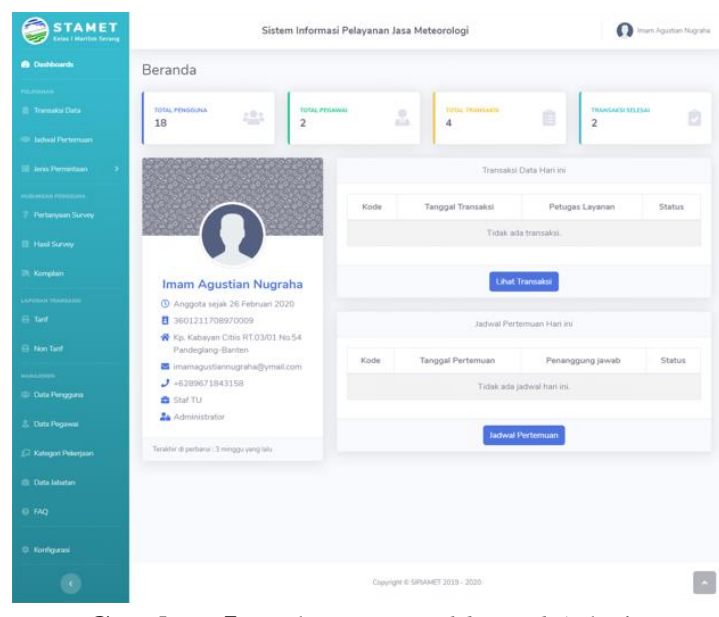

Gambar 5. Halaman Dashboard Admin

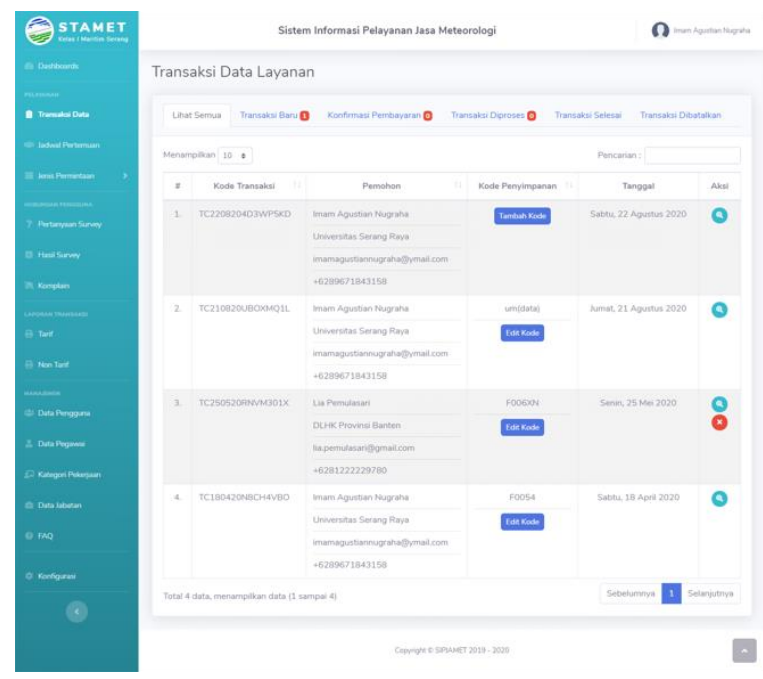

Gambar 6. Halaman Admin Transaksi Data

Halaman admin transaksi data dipergunakan untuk menampilkan transaksi data layanan yang diajukan atau di minta oleh pengguna. Terdapat beberapa tab menu pada halaman ini yaitu, Lihat semua, Transaksi Baru, Konfirmasi Pembayaran, Transaksi Diproses, Transaksi Selesai dan Transaksi Dibatalkan. Untuk melihat detail dari transaksi dapat dengan mengklik button lingkaran yang memiliki icon 
pencarian. Kode penyimpanan pada halaman ini berfungsi untuk menambahkan kode penyimpanan file pada komputer local petugas.
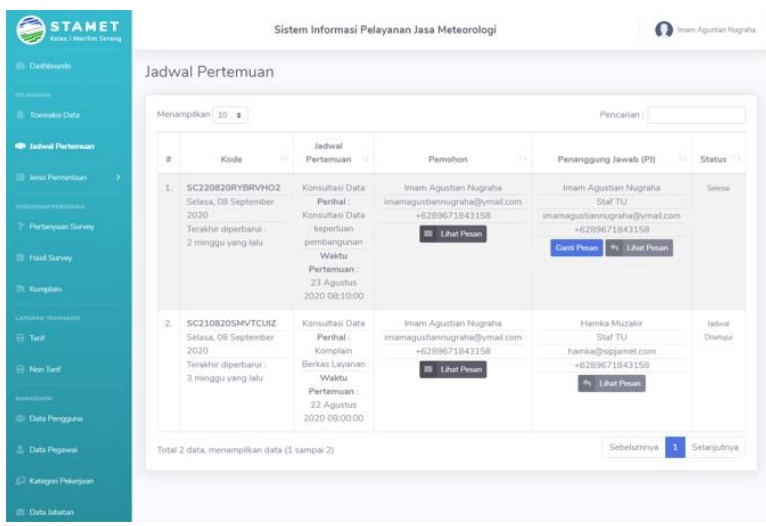

Gambar 7. Halaman Admin Jadwal Pertemuan

Halaman jadwal pertemuan dipergunakan untuk menjadwalkan hasil dari pengguna yang sudah menginputkan jadwal dan akan di proses oleh admin dengan fitur lihat pesan pemohon untuk alasan pertemuan. Setelah melihat pesan, selanjutnya kirim pesan jika ada pesan yang ingin di sampaikan oleh admin.

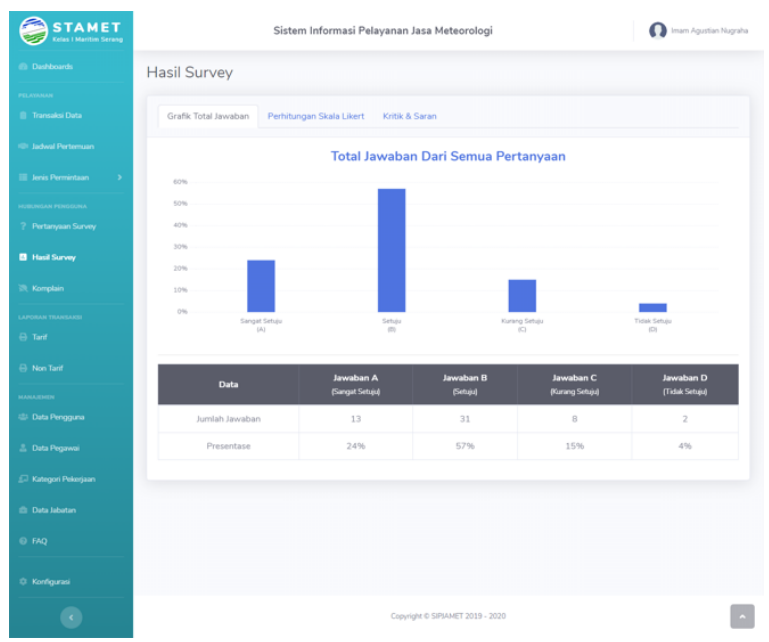

Gambar 8. Halaman Admin Hasil Survey

Pada halaman hasil survey menunjukan hasil grafik survey kepuasan serta kritik dan saran yang telah di input oleh pengguna.

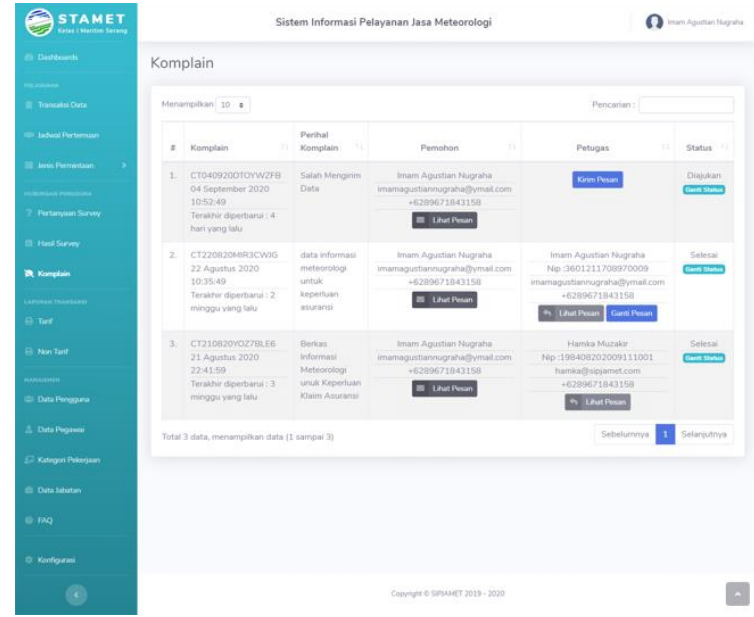

Gambar 9. Halaman Admin Komplain

Pada halaman komplain dimana admin akan melihat pesan dari pengguna dengan isi hasil komplain dari pengguna, kemudian mengirimkan pesan jika di butuhkan, dan ganti status jika komplain sudah terselesaikan.

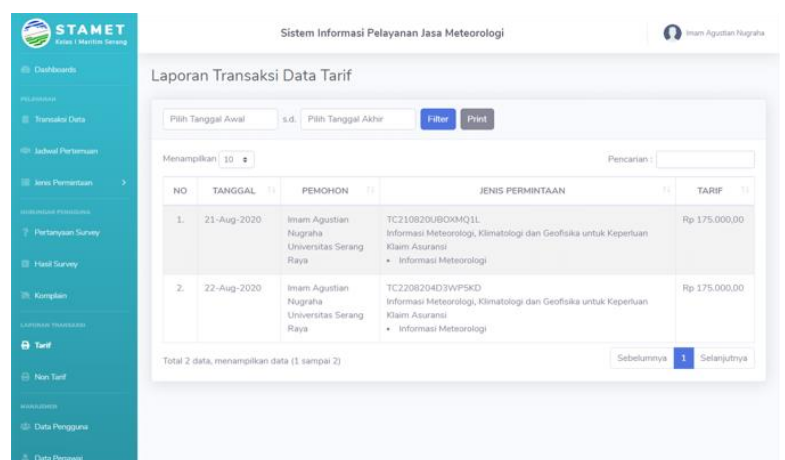

Gambar 10. Halaman Laporan Transaksi

Pada halaman laporan transaksi data tarif dimana admin dapat memfilter sesuai tanggal yang di inginkan dan print terhadap hasil dari laporan transaksi data bertarif.

Berikut ini adalah tampilan halaman website untuk Pengguna: 

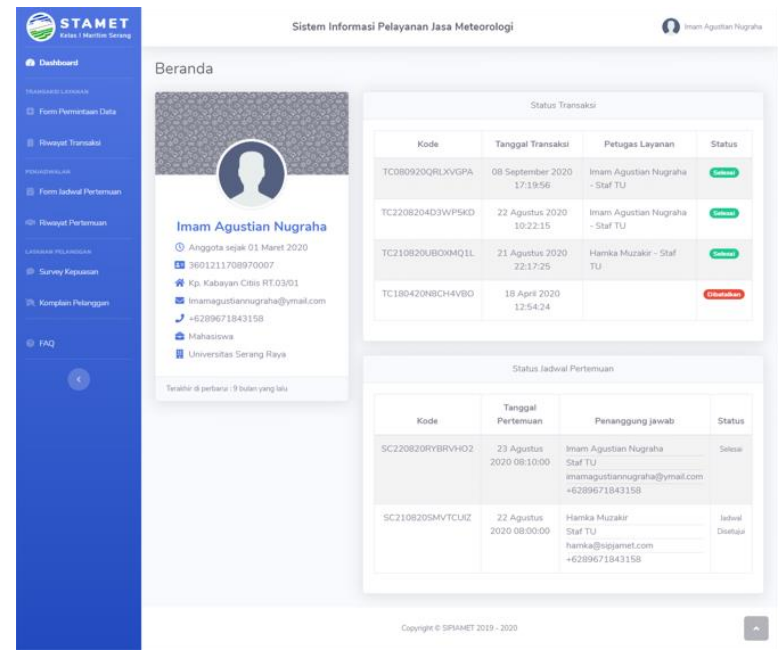

Gambar 11. Halaman Dashboard Pengguna
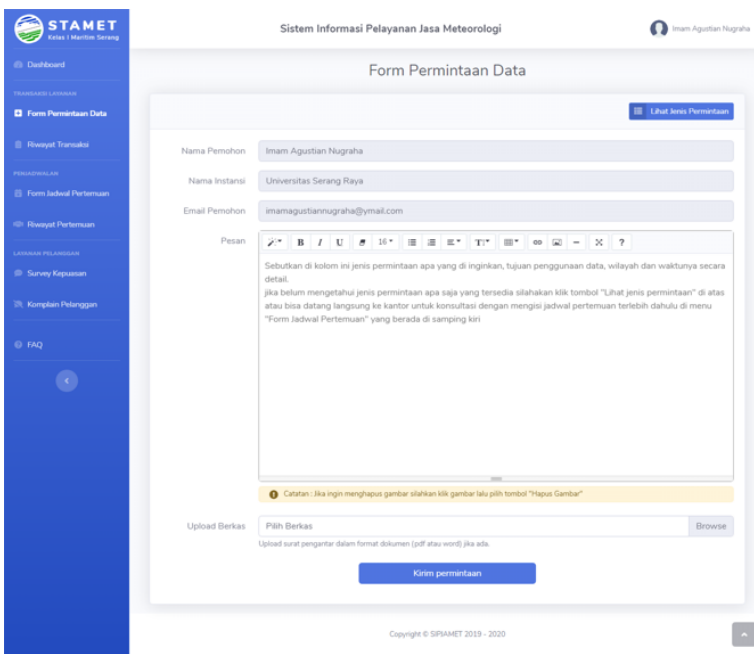

Gambar 12. Halaman Pengguna Permintaan Data

Pada halaman permintaan data dimana pengguna dapat mengisi permintaan data yang di inginkan lalu mengirimkan permintaan kepada admin.
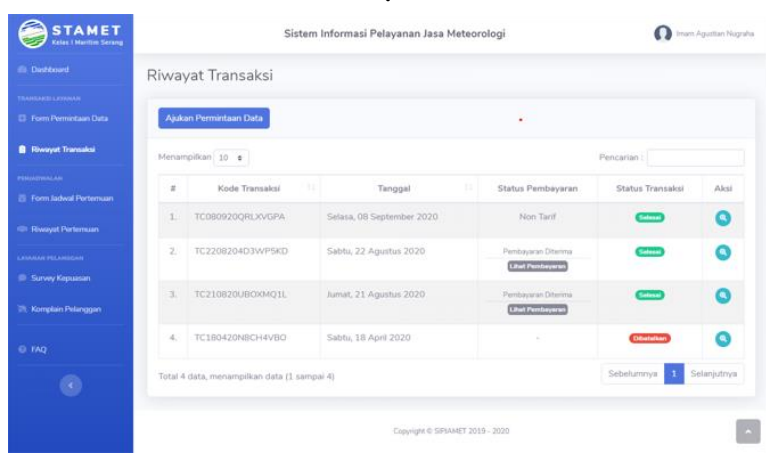

Gambar 13. Halaman Pengguna Riwayat Transaksi

Pada halaman transaksi digunakan untuk melihat transaksi yang telah di input oleh pengguna.
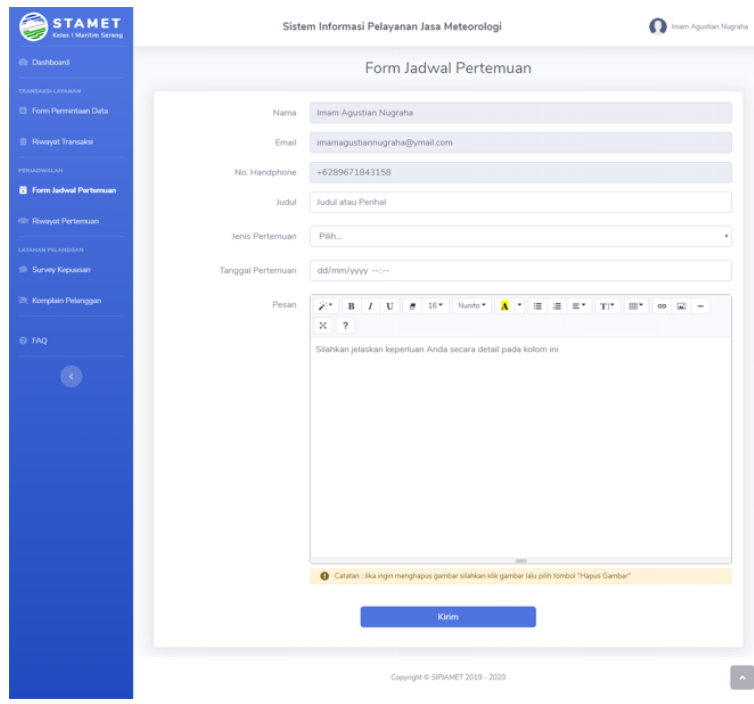

Gambar 14. Halaman Pengguna Jadwal Pertemuan

Pada halaman jadwal pertemuan dimana pengguna akan menginputkan alasan untuk pertemuan dan meminta jadwal untuk pertemuan sesuai yang diinginkan pengguna.

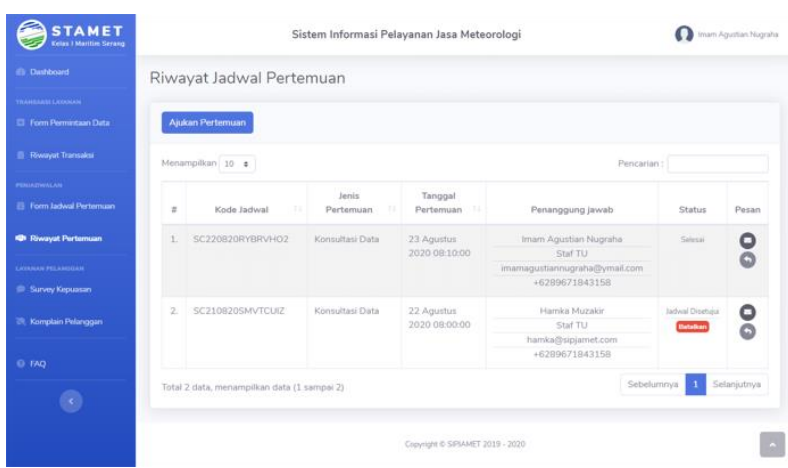

Gambar 15. Halaman Pengguna Riwayat Pertemuan

Pada halaman riwayat pertemuan dimana pengguna melihat hasil pertemuan yang telah di inputkan pada halaman jadwal pertemuan. 


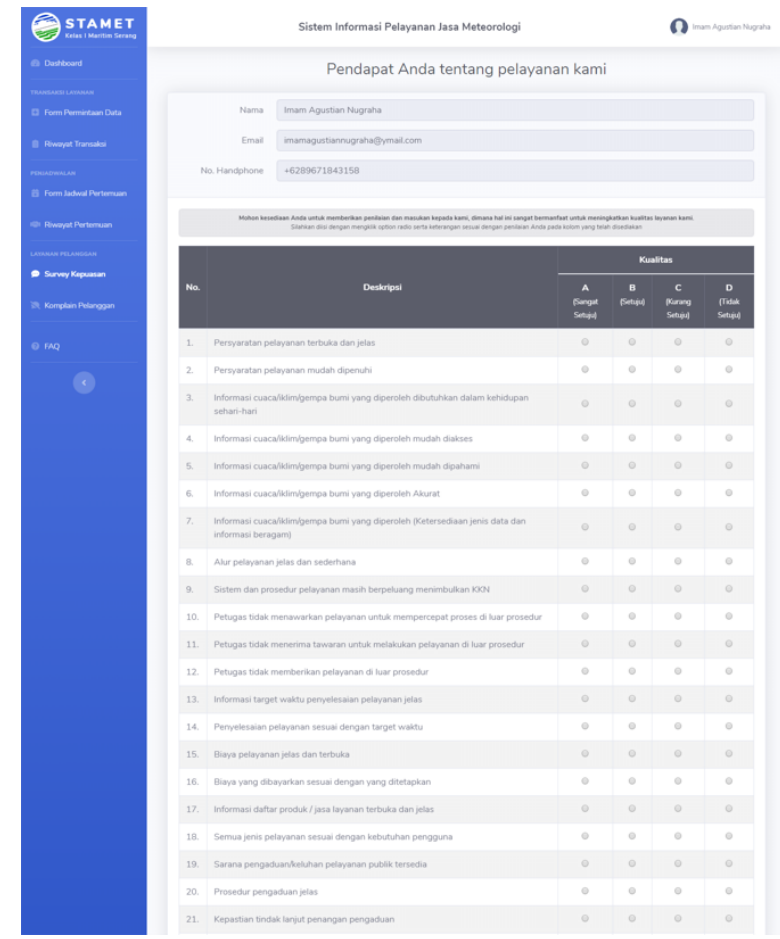

Gambar 16. Halaman Pengguna Survey Kepuasan

Pada halaman survey kepuasan dimana pengguna akan mengisi survey yang telah disediakan oleh sistem untuk meningkatkan pelayanan pada sistem informasi pelayanan jasa meterologi.

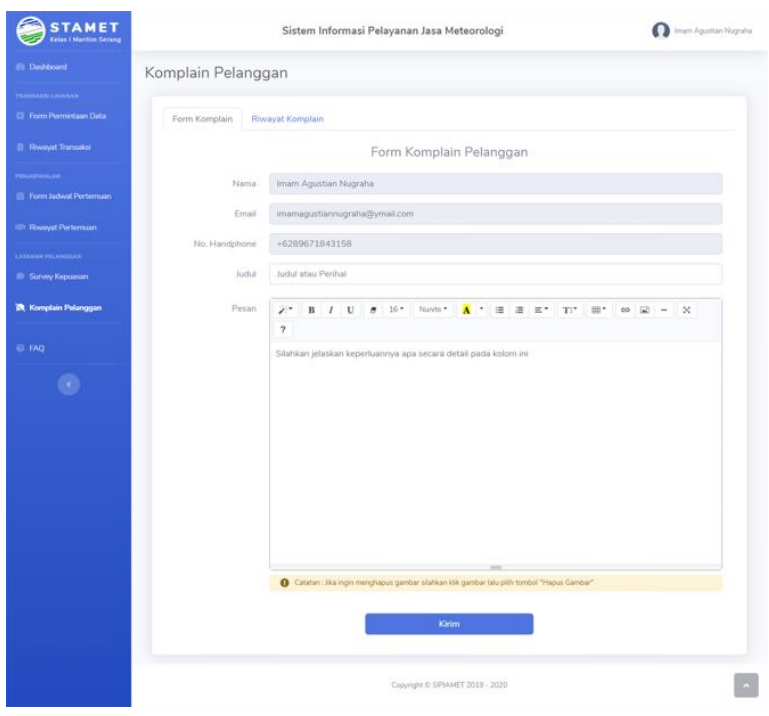

Gambar 17. Halaman Komplain Pengguna

Pada halaman komplain pelanggan digunakan oleh pengguna untuk memberika komplain terhadap sistem untuk memberikan aduan dari pengguna jika ada kesalahan terhadap sistem.

\section{KESIMPULAN}

Berdasarkan uraian dan pembahasan yang telah dikemukakan, dapat diambil kesimpulan bahwa pembuatan Sistem Informasi Pelayanan Jasa Meteorologi yang menggunakan pendekatan Customer Relationship Management (CRM) dimulai dengan pengumpulan data melalui wawancara, observasi, dan studi literatur, dilanjutkan dengan menganalisa kebutuhan sistem, merancang sistem dan membuat prototype sistem. Kemudian dilakukan evaluasi untuk mengetahui apakah prototype sistem yang dibuat sesuai dengan kebutuhan atau tidak, sehingga terjadi proses pengulangan sampai prototype sistem sesuai dengan kebutuhan.

Dengan pembuatan Sistem Informasi Pelayanan Jasa Meteorologi yang mengimplementasikan Customer Relationship Management (CRM) ini, yaitu pembuatan fitur survey kepuasan, kritik dan saran, serta pengajuan komplain, dapat membantu petugas mengetahui berapa tingkat kepuasan pengguna terhadap pelayanan yang diberikan, mempermudah dalam pembuatan laporan dan pencarian transaksi data layanan. Selain itu sistem ini dapat memudahkan pengguna dalam mengajukan komplain dan memperoleh informasi meteorologi tanpa harus datang ke kantor. Hal tersebut menunjukan bahwa sistem yang dibuat dapat meningkatkan efisiensi, transparansi dan akuntabilitas layanan jasa Meteorologi di Stasiun Meteorologi Kelas I Maritim Serang berdasarkan feedback pengguna.

\section{REFERENSI}

[1]. P. Nuralam, "Manajemen Hubungan Pelanggan Perbankan Syariah Indonesia," p. 146, 2018.

[2]. P. T. Prasetyaningrum, "Rancang Bangun E-Crm Pada Perbankan Berbasis Web 2.0 (Studi Kasus Bank Bpd Diy Cabang Utama Yogyakarta)," vol. 6, no. 1, 2015.

[3]. T. Fahrudiansyah and V. Rosalina, "Electronic Customer Relationship Management (E-CRM) Pengelolaan Sampah dalam Upaya Menuju Serang sebagai Smartcity," pp. 135-140, 2018.

[4]. Rosalina, Vidila., Mulyanah, Malik A., "Electronic Customer Relationship Management (E-CRM) Modeling on MSMEs Banten", International Journal of Computer Applications (0975 - 8887) Volume 176, October 2017, New York, USA. 
[5]. Rosalina, Vidila., Mulyanah, Malik A., Perwitasari P., "Model Electronic Customer Relationship Management (ECRM) Menggunakan Adaptasi Bahasa Lokal Pada Usaha Mikro Kecil Menengah (UMKM) Banten", Prosiding Seminar Nasional Riset Terapan : SENASSET 2017 ISBN 978-602-73672-0-3 : 12, November 2017, Serang.

[6]. Rosalina, Vidila., Malik A., Perwitasari E.,."Sosialisasi Manfaat Electronic Customer Relationship Management (ECRM) dalam Upaya Meningkatkan Retensi Pelanggan UMKM Cilegon". Jurnal Pengabdian Masyarakat Wikrama Parahita Vol 1 No 1, November 2017.

[7]. Rosalina, Vidila., Hamdan. "Electronic Customer Relationship Management (ECRM) Modeling As Efforts to Increase Customer Retention of Micro Small and Medium Enterprises (MSMEs) in Banten". International Conference On Computer Science Engineering and Technology : ICComSET 2018, Tasikmalaya, 27-28 November 2018.

[8]. Rosalina, Vidila., Hamdan, Saefudin,.“ Mobile Customer Relationship Management (m-CRM) Application Development in MSMEs Indonesia", Journal of Physic : Conference Series Volume 1179, 2019, Published under licence by IOP Publishing Ltd.

[9]. Rosalina, Vidila, Hamdan, Triayudi A.. "Electronic Customer Relationship Management (E-CRM) Application as Efforts to Increase Customer Retention of Micro Small and Medium Enterprises (MSMEs) in Banten Indonesia" International Journal of Computer Applications - IJCA Volume 182, January 2019, ISSN 0975 - 8887, New York, USA.

[10]. Rosalina V., Munandar Ai, Hidayanto A. N., Santoso H. B., "Citizen Readiness for Adopting Electronic Citizen Relationship Management (e-CiRM) : A Qualitative Exploration", International Conference Islam and Technology (ICONISTECH), 11-12 July 2019 in Bandung.

[11]. Rosalina V, Munandar Ai, Hidayanto AN, Santoso H B, "Measuring Citizen Readiness To Adopt Electronic Citizen Relationship Management (E-CiRM) Using Technology Readiness Index (TRI)", Journal Of Theoretical And Applied Information Technology (JATIT) 15th November 2020. Vol.98. No 21. ISSN: 1992-8645 E-ISSN: 1817-3195
[12]. Vidila Rosalina, Tb Ai Munandar and Achmad Nizar Hidayanto. Electronic Citizen Relationship Management (eCiRM) Modeling towards Serang as a Smart City. International Journal of Computer Applications 175(25):27-32, October 2020.

[13]. G. Aziz and L. P. Hasugian, "Operational Customer Relationship Management Pada Sari Good Bakery," vol. 12, no. 2, pp. 212-221, 2019.

[14]. R. Adlan, W. Agustin and Y. Efendi, "Rancangan Website E-CRM ( Electronics Customer Relationship Management ) Pada House Of Smith Pekanbaru," vol. 3, no. 2, pp. 9-18, 2019.

[15]. I. P. A. E. Pratama, Sistem Informasi Dan Implementasinya, Bandung: Informatika, 2014.

[16]. R. A. S and M. Shalahuddin, "Rekayasa Perangkat Lunak Terstruktur dan Berorientasi Objek," Bandung, Informatika, 2016, p. 295.

[17]. M. Akif, Y. A. Prasetyo and N. Ambarsari, "Pengembangan Aplikasi ECRM Bojana Sari Menggunakan Metode Prototype," vol. 2, no. 1, pp. 1057-1070, 2015.

[18]. D. Purnomo, "Model Prototyping Pada Pengembangan Sistem Informasi," Jurnal Informatika Merdeka Pasuruan, vol. 2, 2017. 